\title{
Methodological Considerations for Modeling Social Vulnerability and COVID-19 Risk-Response to Nayak et al.
}

J Gen Intern Med 36(4):1115-6

DOI: $10.1007 / \mathrm{s} 11606-021-06601-2$

(C) Society of General Internal Medicine 2021

To the Editor:

We thank Nayak and colleagues for their interest in our study, which examined the correspondence between the Center for Disease Control's Social Vulnerability Index (SVI) and county-level COVID-19 cases and deaths. ${ }^{1}$ In light of the mentioned methodological differences with their team's preprint, we welcome this opportunity to explore the implications of risk adjustment choices when modeling population-level health inequities.

The growing body of literature on how COVID-19 differentially impacts marginalized populations highlights the need to be cautious when adjusting for clinical and sociodemographic variables. $^{2-4}$ In our study, we avoided adjusting for comorbidities because they fall on the causal pathway from social vulnerability to disease incidence and mortality. ${ }^{2}$ Furthermore, overadjustment bias in risk prediction and resource allocation models may mislead policymakers to conclude that smaller differences after adjustment reflect smaller disparities, rather than recognizing that comorbidity rates themselves are a consequence of longstanding structural inequity. ${ }^{5}$ With these issues in mind, we remain concerned that controlling for comorbidities may mask the starkness of COVID-19 inequities.

We also chose not to adjust for age because the county-level proportion of residents $\geq 65$ years was already included within the Household Composition \& Disability SVI domain. Still, a role exists for age-adjustment when granular data are available. When Gross and colleagues ${ }^{3}$ used indirect standardization to compare expected and observed COVID-19 mortality rates by race/ethnicity within age strata, they found that ageunadjusted mortality rates may underestimate disparities among populations that skew younger (e.g., Black and Latinx). Although we found that the most vulnerable counties in the Minority Status and Language domain had an almost fivefold increased risk of cases and deaths compared to the least vulnerable counties, ${ }^{1}$ Gross and colleagues demonstrate that this disparity may be even more dramatic.

Received December 7, 2020

Accepted January 1, 2021

Published online January 19, 2021
We return to a takeaway consistent across the COVID-19 disparities literature: addressing the uneven burden of the pandemic requires structural interventions to prioritize equity for marginalized communities. ${ }^{4}$ Recognizing the implications of adjustment in risk prediction and resource allocation models is crucial to achieving this goal. We are encouraged by recent guidance from the National Academies of Science, Engineering, and Medicine recommending the use of the SVI or another vulnerability index to ensure equitable allocation of SARS-CoV-2 vaccines across the USA, ${ }^{6}$ and are eager to continue investigating strategies to mitigate the pandemic's devastating toll on vulnerable communities.

Rohan Khazanchi, $B A^{1}$

Evan R. Beiter, $B A^{2}$

Ishani Ganguli, MD MPH ${ }^{2,3}$

${ }^{1}$ College of Medicine, University of Nebraska Medical Center,

Omaha, NE, USA

${ }^{2}$ Harvard Medical School,

Boston, MA, USA

${ }^{3}$ Division of General Internal Medicine \& Primary

Care, Department of Medicine, Brigham \&

Women's Hospital,

1620 Tremont St, Third Floor, Boston, MA 02120 , USA

Corresponding Author: Ishani Ganguli, MD MPH; Division of General Internal Medicine \& Primary Care, Department of Medicine, Brigham \& Women's Hospital, 1620 Tremont St, Third Floor, Boston, MA 02120, USA (e-mail: iganguli@bwh.harvard.edu).

\section{Compliance with Ethical Standards:}

Conflict of Interest: Dr. Ganguli reports receiving consulting fees from Haven, Blue Cross Blue Shield Massachusetts, and F-Prime Capital for work unrelated to this research. All other authors have no relevant conflicts of interest to report.

\section{REFERENCES}

1. Khazanchi R, Beiter ER, Gondi S, Beckman AL, Bilinski A, Ganguli I County-Level Association of Social Vulnerability with COVID-19 Cases and Deaths in the USA. J Gen Intern Med. 2020; 35(9):2784-2787. https:// doi.org/10.1007/s11606-020-05882-3

2. Kim SJ, Bostwick W. Social Vulnerability and Racial Inequality in COVID19 Deaths in Chicago: Health Educ Behav. Published online May 21, 2020. https://doi.org/10.1177/1090198120929677 
3. Gross CP, Essien UR, Pasha S, Gross JR, Wang S, Nunez-Smith M Racial and Ethnic Disparities in Population-Level Covid-19 Mortality. J Gen Intern Med. 2020; 35(10):3097-3099. https://doi.org/10.1007/ s11606-020-06081-w

4. Khazanchi R, Evans CT, Marcelin JR. Racism, Not Race, Drives Inequity Across the COVID-19 Continuum. JAMA Netw Open. 2020; 3(9):e2019933-e2019933. https://doi.org/10.1001/jamanetworkopen. 2020.19933

5. Schisterman EF, Cole SR, Platt RW. Overadjustment Bias and Unnecessary Adjustment in Epidemiologic Studies. Epidemiology. 2009; 20(4):488495. https://doi.org/10.1097/EDE.0b013e3181a819a1
6. Schmidt H, Pathak P, Sönmez T, Ünver MU. Covid-19: how to prioritize worse-off populations in allocating safe and effective vaccines. BMJ. 2020; 371. https://doi.org/10.1136/bmj.m3795

Publisher's Note: Springer Nature remains neutral with regard to jurisdictional claims in published maps and institutional affiliations. 